\title{
TOURIST PHOTOGRAPHY AND THE REVERSE GAZE
}

(To be published in Ethos, 2006)

Alex Gillespie (alex.gillespie@stir.ac.uk)

Department of Psychology

University of Stirling

Stirling, FK9 4LA

Scotland

UK

Tel: + 44 (0) 1786466841

Fax: + $44(0) 1786467641$

By-line: Alex Gillespie is a Lecturer in Social Psychology in the Department of Psychology, University of Stirling, Scotland.

Running head: The reverse gaze 


\section{ABSTRACT}

The interaction between tourist photographer and local photographee is a dynamic site of identity construction. To date, this interaction has been theorized mainly in terms of the power of the tourist photographer, which has been shown to mediate and commodify local cultures and create new identities amongst those photographed. The present article contributes a change of emphasis by examining the socio-psychological dynamics of the reverse gaze and its role in constructing the emerging identity of the photographer. The reverse gaze refers to the gaze of the photographee upon the photographer as perceived by the photographer. Data from Ladakh, a popular backpacker tourist destination in northern India, illustrates how the reverse gaze of Ladakhis can constitute the emerging tourist self, stimulating uncomfortable social emotions, such as embarrassment. The question raised by the article is, what socio-psychological processes constitute the power of the reverse gaze to position the tourist photographer? The article argues that tourists, when they feel the reverse gaze, are not taking the actual perspective of Ladakhis, but are instead attributing their own critical attitudes toward other tourist photographers to the Ladakhi photographee. Thus the discomfort that a tourist in Ladakh feels when caught in the reverse gaze, it is argued, is a product of that tourist being positioned in the same disparaging way as that tourist usually positions other tourist photographers. Key Terms: Tourism, Reverse Gaze, India, George Herbert Mead, Positioning, 
The interaction between tourist photographer and local photographee is a clearly identifiable genre of interaction that is reproduced, in various ways, across the world. Concepts in tourism research, such as Urry's (1990) 'tourist gaze,' have tended to endow the tourist behind the camera with much power (e.g., Crawshaw and Urry 1997). The tourist gaze, objectified in the camera, is said to have the power to create a cultural revival (Bruner 2005:119), commodify local culture (Philip and Mercer 1999) and cultivate new forms of self-consciousness amongst the local citizens (Tilley 1999). However, the photographer-photographee relation is a complex interaction with at least two sides (Cohen et al. 1992). It is not only the photographee who is influenced by the interaction, so too is the photographer. The photographer-photographee interaction is a boundary (Barth 1969). At this boundary, the dynamic and situated emergence not only of the photographee self, but also of the tourist photographer self, is evident. The photographee can gaze upon the tourist photographer, and this "reverse gaze" can play an important role in constituting the emerging self of the tourist photographer.

\section{CHARACTERIZING THE REVERSE GAZE}

The reverse gaze is clearly evident in an unusual interaction that I observed during fieldwork in Ladakh, northern India. The interaction occurred at a cultural festival that had been arranged by Women's Alliance, a local NGO, in order to display Ladakhi culture to Western tourists. The audience comprised a couple of hundred foreign tourists and 
Ladakhis sitting and standing in a wide circle. At the centre of the circle was an open space where troupes of traditionally dressed Ladakhi women took turns to sing and dance. In this type of situation it is expected that tourists will take photographs, and most tourists were availing of the opportunity. However, not all the tourist cameras were trained upon the dancing women. Several tourists were openly photographing traditional-looking Ladakhis in the audience.

Figure 1: My photograph of a tourist photographing a traditionally dressed Ladakhi woman

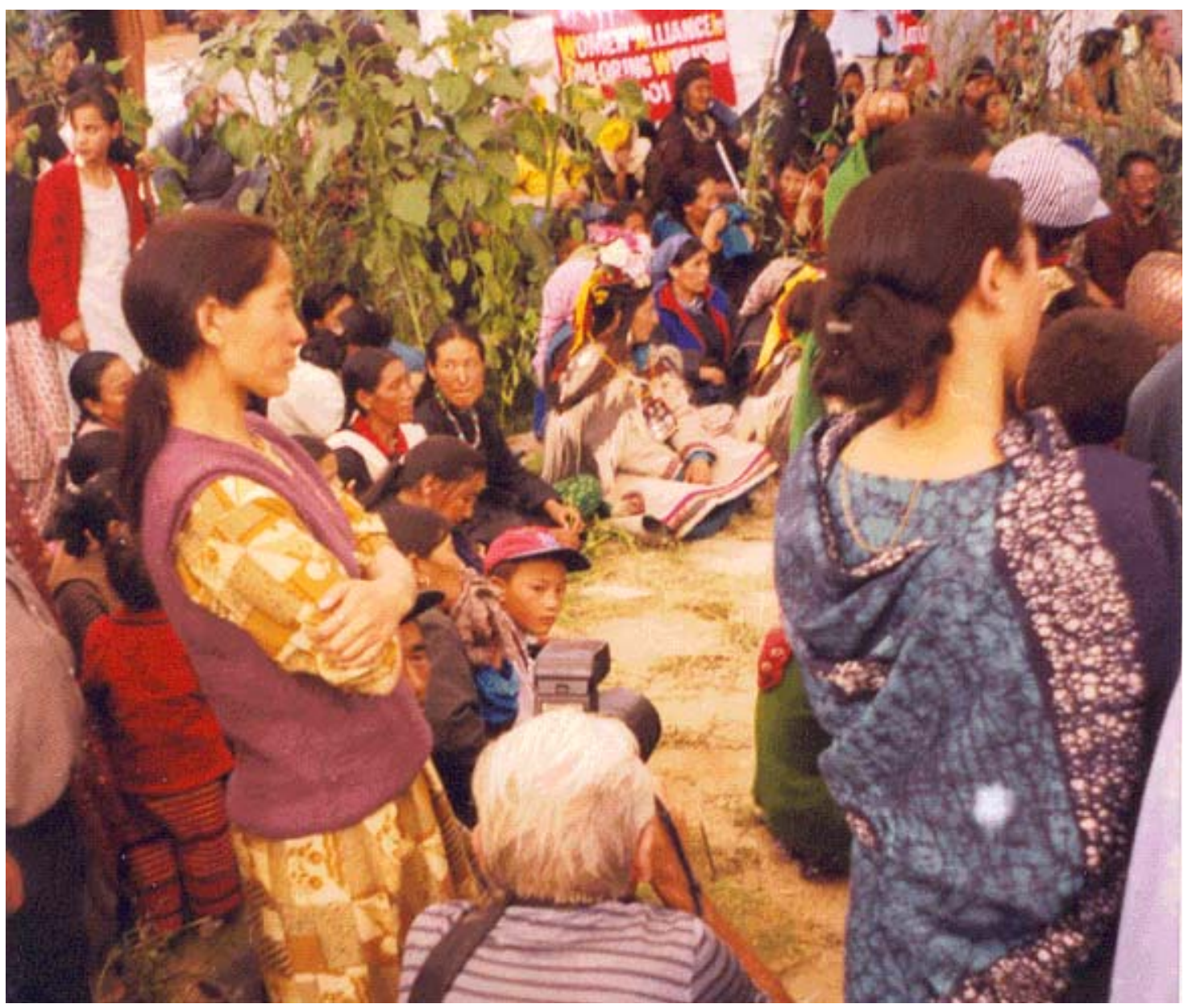


Figure 1 shows a picture I took of a Ladakhi woman being photographed by a French tourist with a telephoto lens. This particular Ladakhi comes from the remote village of Drass. She is wearing a homespun woolen dress, with traditional jewelry and traditional shoes. Adorning her head is an impressive arrangement of flowers. In many ways she crystallizes tourists' imagination of Ladakh. Tourists visit Ladakh expecting it to be broadly equivalent to Tibet (Dodin and Räther 2001). As with Tibet, Ladakh is imagined to be spiritual and timeless, and Ladakhis are imagined to practice colorful traditions (Bishop 1989; Lopez 1998). The dress and manner of this Ladakhi woman, more than many other Ladakhis at the festival, conformed to these expectations. Accordingly, she was the focus of many tourist cameras. Indeed, during the course of fourteen minutes I counted twenty-one different tourists photographing her. Some of the tourists requested if they could take her photograph, and some even posed with her, but the majority did not ask for permission. Overall she was obliging, though noticeably she did joke with one tourist by pretending to dodge the tourist's photographic gaze. The Frenchman in Figure 1 was the most active photographer that I observed. He followed the Ladakhi woman around the festival taking photographs, and when she sat down, he took up his position in Figure 1. By this time, the Frenchman's relentless photographing had been noticed by other tourists.

Shortly after I took the photograph in Figure 1, a female tourist, nearby the photogenic Ladakhi woman, offered the Ladakhi her camera while pointing toward the Frenchman. The Ladakhi woman accepted the camera and began pointing it toward the French photographer, and me, behind him. She was imitating or "ventriloquating" the actions of tourists she had seen so many times before. Figure 2, another photograph taken by me, 
shows the amusement on the face of the Ladakhi photographer, her colleagues and the tourist who lent her camera to the Ladakhi. In terms of the reverse gaze, the interesting outcome of this interaction was in the manifest embarrassment of the French tourist. The numerous gazes that the Ladakhi woman had been attracting became aware of the camera she held, and they followed its line of sight toward the Frenchman. The gaze of the other tourists combined with her mimicry to create a moment of confusion. As a consequence, his face flushed, and his actions became awkward. As Figure 2 shows, he lowered his telephoto lens. While I could slip my camera into my pocket, his large camera became painfully conspicuous. The tourist in the left of Figure 2 had previously been photographing the photogenic Ladakhi woman also, and he, unable to hide his camera, simply began to photograph, or at least pretend to photograph, someone or something else. Shortly after the photograph in Figure 2 was taken the French tourist briefly pursued a similar strategy, before standing up and leaving the festival area. Given that he could not ignore the reverse gaze, he decided to simply break off the discomforting interaction.

One could argue that the French tourist was perturbed by the disturbing novelty of this interaction, or simply by being caricatured, but such explanations do not go far enough. The origin of flushing is not simply in the individual's physiological response, it is in the social situation, particularly in the individual's understanding of other people's perspectives. The feeling of embarrassment implies a discrepancy between Self's image of Self and Self's image of how Other perceives Self (Edelman 1987). The embarrassment of the French tourist indicates that his image of himself has altered, not necessarily in a fundamental way, but simply that within this interaction, he has been re-positioned (Holland et al. 1998). And the manifestly social nature of his discomfort, the blushing, 
indicates that the mechanism underlying this re-positioning is to be found in the social situation.

Figure 2: My photograph of the traditionally dressed Ladakhi woman photographing a $\underline{\text { tourist }}$

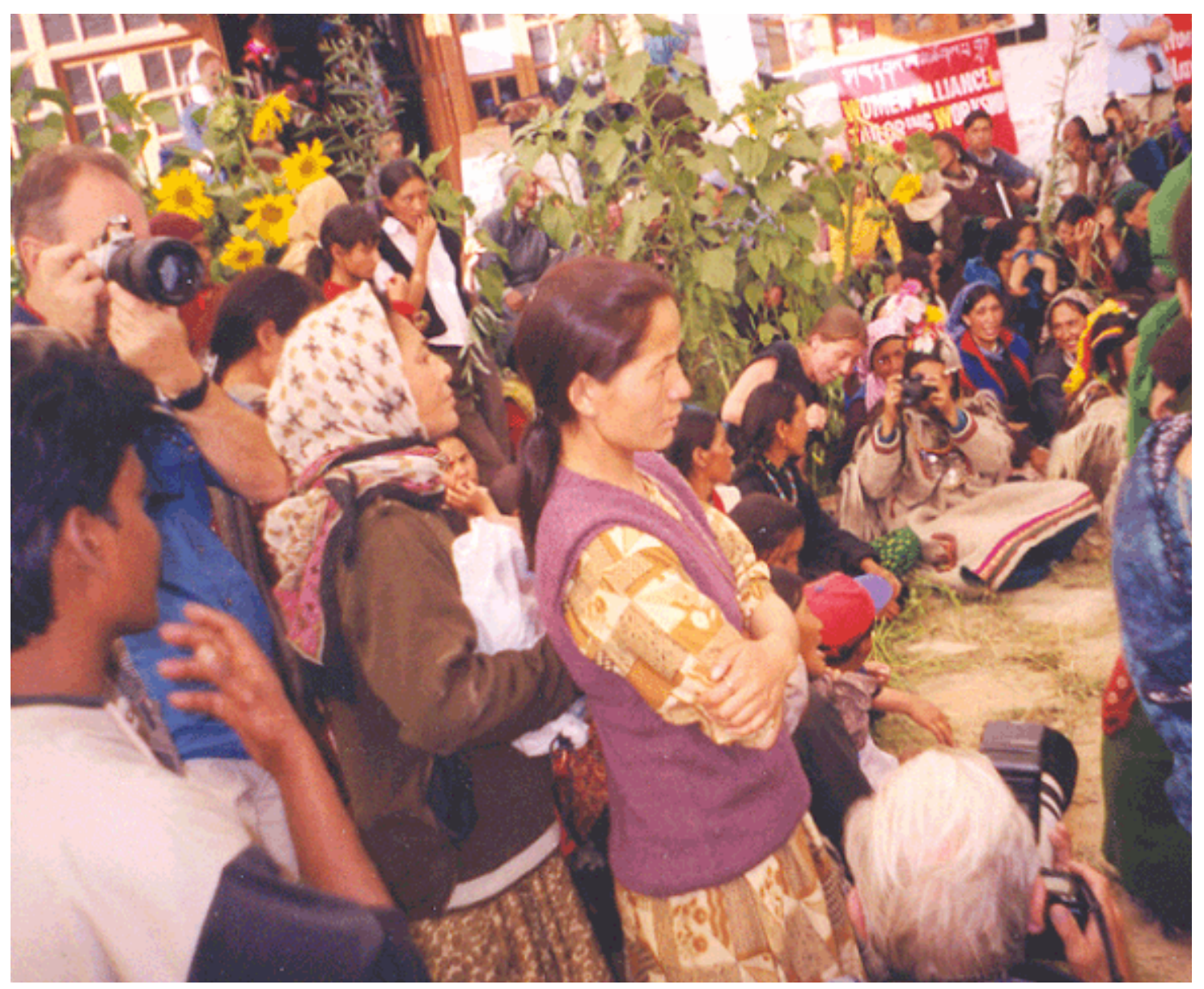

During the course of over twelve months of fieldwork, ${ }^{1}$ this is the only time that I saw a Ladakhi take a photograph of a tourist without the tourist requesting it - though noticeably in this case a second tourist has, in some sense, made the request. As such, the interaction I have reported is highly unusual. Yet, this interaction exemplifies the dynamics of the 
reverse gaze, which in a less dramatic way is a necessary potential in all photographerphotographee interactions. The photographee, by a prolonged stare, a questioning look, or even just a raised eyebrow, can momentarily reverse the relationship between photographer and photographee. In a glance the photographee can, like the Ladakhi woman with the camera, capture and objectify the tourist photographer as a particular type of tourist. That is to say, the reverse gaze, in its various forms, can mediate the emerging tourist self.

The power and pervasiveness of the Ladakhi reverse gaze is evident in the diverse ways that tourists ${ }^{2}$ try to avoid it. For example, some tourists pretend to photograph a landscape or a building which is in the same general direction as the target Ladakhi. The camera is then focused upon something roughly equidistant. Then with a sideways sweep, the target Ladakhi is photographed quickly and unsuspectingly. A development of this method is to take photographs without looking through the lens at all (this is the method which I used when taking the photographs in Figure 1 and Figure 2). Using an automatic focus camera, the strategy is to simply, and swiftly, point the camera in the right general direction and take the photograph. With practice this can be done so quickly that it almost dissolves into a fluid motion. Digital cameras greatly facilitate this method because they reduce the cost of wasted photographs. Surreptitiously using a telephoto lens from a distance is yet another popular strategy to avoid the reverse gaze.

One of the most extreme strategies for avoiding the reverse gaze is to either travel without a camera or to hide one's camera. For example, I met one Australian who, when staying in a gonpa (Buddhist monastery), and meeting with monks, hid his camera despite his 
awareness that he was missing some of the best photographic opportunities that he had encountered. When I asked him why he did this, he said:

It’s the Ladakhis' perception of me taking a photo - if I have a camera, I am a tourist, whereas if I don't, that thought is not so prominent in their minds. Like say they look at me taking a photo and say "there is another tourist taking a photo"

The reverse gaze has the power to constitute this Australian as "another tourist taking a photo.” Being just “another tourist” is an undesirable self-image. This Australian had made an effort not to stay in a guesthouse or hotel and instead had gone out of his way to stay in a gonpa. He did not make this effort in order to be constituted as just "another tourist.” Accordingly, he engages in self-presentation (Goffman 1959), trying to control the impression that he makes on the Ladakhi monks. By not wielding a camera he hopes that he can occupy a more favorable, and more unique, position within the reverse gaze. Although it was important for this tourist to capture his experiences on film, in this situation it was more important for him to avoid the reverse gaze. In this situation the photographic gaze was subordinated to the reverse gaze.

As an initial starting point, we can characterize the reverse gaze as referring to the gaze of the photographee on the tourist photographer. It is evident that the reverse gaze can cause discomfort, in the form of embarrassment, shame, or a spoilt identity. Indeed, there is no evidence of tourist photographers, in Ladakh, beaming with pride or satisfaction when caught, with a camera, in the reverse gaze. But why does the reverse gaze cause such discomfort for tourist photographers? The present article addresses this question. 
However, in order to do so we will need to examine the social psychological mechanism underlying the reverse gaze. Specifically, given the vast cultural gulf between tourists and Ladakhis, how do tourists begin to comprehend the reverse gaze of Ladakhis?

\section{TAKING THE PERSPECTIVE OF LADAKHIS?}

One way to explain tourist photographers' manifest discomfort when caught in the reverse gaze of Ladakhis comes from the tradition of Symbolic Interactionism (Blumer 1969). In accordance with the theories of Cooley (1902) and Mead (1913), it has been argued that embarrassment, empathy, self-reflection and self-presentation arise through people taking the perspectives of others (Charon 1979). Accordingly, one could explain the power of the reverse gaze over tourist photographers in terms of tourists taking the perspective of Ladakhis. This approach would explain the manifest embarrassment of the French tourist as follows: The Ladakhi being photographed has a negative conception of tourist

photographers. Tourists, when they are caught in the reverse gaze become aware, to some extent, of this negative image in the mind of the Ladakhi photographee and it is this feeling of going against the wishes of the Ladakhis that creates the discomfort because it positions the tourist photographer as an ignorant and superficial tourist.

The evidence from the tourist side of the photographer-photographee interaction clearly supports this interpretation. There is some debate amongst tourists (and dialogically within some tourists) regarding what Ladakhis think about tourists. Some tourists argue that Ladakhis idolize tourists' modern lifestyle and wealth, while others argue that Ladakhis resist modernization and are struggling to hold onto their culture in the face of tourism. 
However, when the focus is narrowed down to how Ladakhis feel when being photographed by tourists, there is strong agreement: tourists think that Ladakhis do not like being photographed. While exceptions are made if the photographer and photographee know each other, in cases where the photographer has not had any relation with the Ladakhi there is no exception. In such cases the consensus is that Ladakhis feel objectified by tourist photographers. The following excerpt, from a discussion I had with some young English backpackers, clearly illustrates the general perception:

Barry: I try not to be, em, to take pictures of the people, though, em, I want to [...] Tom: I feel embarrassed to do it, because it is like, like making them feel freakish Barry: It's like “look at the freaks there!” - that's just horrible for the people

Tom states that taking photographs of the Ladakhis makes "them feel freakish," and Barry corroborates this opinion by saying that it is "just horrible” for the Ladakhis. From exchanges such as this, one gets the impression that to take a photograph of a Ladakhi is to ride roughshod over Ladakhi sensibilities. Assuming that this is how Ladakhis feel when photographed without permission, and empathizing with this feeling, could clearly explain why tourist photographers, when caught in the reverse gaze, feel uncomfortable. Thus, following this line of argument, the explanation of tourists' discomfort when caught in the reverse gaze is that they empathize with the feeling of disrespect that Ladakhis feel upon being photographed.

However, an examination of the Ladakhi side of the interaction reveals a complication. There is, in fact, little evidence to suggest that Ladakhis feel as oppressed by tourist 
photographs as tourists suspect. And thus, there is little evidence to suggest that tourists are taking the actual perspective of Ladakhis. In order to properly unpack the impression that tourist photographers create in the minds of Ladakhis, it is necessary to consider the broad context of tourism in Ladakh.

Due to border conflicts with Pakistan and China, the Indian government did not allow foreign tourists to visit Ladakh until 1974. Up to that that point, Ladakh was one of the least developed regions of India. Since the early 1980s, between ten and twenty thousand foreign tourists have visited Ladakh annually (Singh 1997). Given that the population of Ladakh is only about a hundred and fifty thousand, this constitutes a considerable influx. The majority of these tourists come from Western Europe (Government of Jammu and Kashmir 1998), and by Ladakhi standards, are wealthy. Accordingly, tourism has had a massive impact on developing the financial economy of Ladakh. Jina (1994:136), for example, estimates that about half of the GDP of Ladakh comes from tourists. Tourism has created jobs and economic wealth, both of which are widely appreciated by Ladakhis.

From the Ladakhi point of view, tourists are a means toward economic development. In order to promote tourism, free festivals, such as the Women's Alliance festival and the Ladakh Festival, are organized. Such festivals, although they expensive to organize and do not produce any direct profits (they are free for tourists), are seen to contribute to the overall economic development of Ladakh by promoting tourism. Furthermore, there is a sense in which individual Ladakhis, by welcoming tourists and by posing for photographs, are also contributing to the development of Ladakh. This attitude is reflected in the fact that, unlike elsewhere (e.g., Bruner 2005:117-118), it is rare that Ladakhis ask for 
financial compensation for posing for photographs. Returning to the Women's Alliance festival, it is worth pointing out that the Ladakhi photographee had chosen to attend this festival of Ladakhi culture knowing that it was organized for tourists and doing so wearing her traditional dress (i.e., not her everyday dress). The Women’s Alliance organizers had requested that women come dressed in traditional dress. The women came in their traditional dress in order to represent and preserve their culture, and were expecting photographs as a result. Indeed, while at this festival an elderly Ladakhi man, also in traditional dress, engaged me in conversation and encouraged me to take photographs of the Ladakhis. He had noticed that I was more interested in photographing tourists than Ladakhis.

The desire to be photographed is most evident amongst the Ladakhi children. They often follow tourists chanting "one photo, one photo" - meaning that they want the tourist to take a photograph of them. Again it is very unusual for these children to request money for being photographed. Rather, it seems, they get an identity reward, or some form of recognition, by virtue of being photographed - it positions them as valuable. On some occasions I have seen tourists get so many requests from children that the tourists have resorted to pretending to take photographs.

Why are Ladakhi adults and children generally enthusiastic about being photographed? The impression that tourist photography has made on Ladakhis is that they have an important culture that is revered across the world. In discussions with Ladakhis it repeatedly emerged that tourism gives Ladakhis pride in their culture. Before tourists were allowed into Ladakh, in 1974, Ladakhis conceived of themselves as "backward” and 
undeveloped (e.g., Galwan 1923). Since the mid 1970s, Ladakhis have become increasingly aware of themselves as possessors of a unique "culture.” Now Ladakhis feel the need to preserve and represent their “culture.” Indeed, there have even been calls for Ladakh to gain independence from the State of Jammu and Kashmir due to having a “unique culture” (van Beek and Bertelsen 1997:52; Wangyal 1997).

Examining the Ladakhi construction of "Ladakhi culture" reveals that it is comprised largely of the things that tourists photograph. It is as if whatever tourist photography has focused upon has become "culture" for the Ladakhis. The traditional dress, the dances, the monasteries, and the religious paintings are all fundamental to "Ladakhi culture." Consider the following excerpt from an elderly Ladakhi woman who has just been asked why tourists visit Ladakh:

They come here to see our typical dress, gonchha and all. They find it beautiful. They take photographs wherever they find an old man with a prayer wheel in his hand, they see who is wearing big earrings, and who has a long beard and they take pictures of them. They don't come here to see the new generation, as they don't take any pictures of them [...] they are here to see our culture

The tourists, she says, are here to see the "culture," to see the old men wearing the gonchha (a traditional maroon overcoat), and not the younger generation. The "new generation" does not wear the gonchha or earrings, and the tourists, she says, "don't come here to see the new generation, as they don't take any pictures of them.” The point is that photography is essential to her train of thought. The woman uses what tourists photograph 
to determine what tourists find "beautiful" and are interested to see. Moreover, that which tourists photograph is positively valued, while that which they do not photograph, the young people, is not valued. While the role of photography in constructing local visions of Ladakhi culture indicates an element of “inventing tradition” (Hobsbawm and Ranger 1983) through tourism (Tilley 1999), it would be overly cynical to think of the emerging discourse of Ladakhi culture as a charade. Ladakhis take their culture very seriously because it is a fundamental component of their current identity.

The most negative views toward tourist photography, that I have heard, came from some young male Ladakhi tour guides who, with the help of some Indian rum, were speaking openly. One of the group provocatively stated that tourists visit Ladakh in the same way as tourists visit a zoo. While some of his colleagues agreed, others strongly resisted the idea, arguing that tourists make an effort to learn Ladakhi, that they eat Ladakhi food and that they are interested in Ladakhi culture because they do not have their own culture. I have also heard reservations about tourist photography from a couple of elderly Ladakhis, who voiced concern about whether the photographs portray Ladakhis in a respectful manner. It is disrespectful, they argued, to photograph Ladakhis when they are working or in work dress. However, if the Ladakhi photographee is dressed in his or her traditional dress, then being photographed should be a source of pride for Ladakhis. Accordingly, the suspicion of tourist photographers that has been noted in other societies (Cohen et al. 1992; Bruner 2005:219), while not absent, does seem to be much attenuated in Ladakh.

This is not to say that Ladakhis have an unconditionally positive view of tourists. Ladakhis commonly criticize tourists for wearing disrespectful dress, especially in the 
monasteries, and for displaying affection in public. Those who work with tourists also quite openly criticize tourists for being mean with their wealth. The point I am making, however, is more specific: taking photographs of Ladakhis in traditional dress is rarely perceived to be disrespectful.

Returning to the theoretical issue at stake: whether tourist photographers are taking the actual perspective of the Ladakhis being photographed, it should be clear that it cannot be so simple. Overall, tourists feel the reverse gaze to be critical of tourist photography. For this reason tourists, as described, fear the reverse gaze. However, the Ladakhis are rarely as critical of tourist photography as tourists fear. Indeed, Ladakhis are often enamored by tourist photography and get a sense of pride through it. Given this attitude amongst Ladakhis it follows that if tourists were taking the actual perspective of Ladakhis they would necessarily sometimes feel good when taking photographs of Ladakhis in traditional dress because they would recognize it as giving a compliment or gesture of recognition, but I have found little evidence of this. Accordingly, the idea that the power of the reverse gaze over tourists stems from tourists literally taking the perspective of Ladakhis must be abandoned in favor of a more subtle interpretation.

\section{RE-CONCEPTUALIZING THE PROBLEMATIC}

George Herbert Mead's phrase “taking the perspective of the other” is widely cited. Yet, there is considerable uncertainty about what the phrase actually means. Some have criticized the concept as an act of mind-reading (e.g., Gergen 1999:125), and empirically it has been demonstrated that humans are actually quite poor at taking each others’ 
perspectives (Shrauger and Schoeneman 1979; Lundgren 2004). But a closer reading of Mead $(1913,1925)$ suggests that he is not writing about people taking the "actual” perspective of others. Instead, he argues, that Self generalizes Self's own experience into the perspective of Other. Because Self and Other are usually embedded in the same social structure, and because Self and Other exchange positions within this social structure, so both Self and Other accumulate equivalent experiences, and are thus able to take each others’ perspectives to some degree (Gillespie 2005).

Applying this reading of Mead to the tourists in Ladakh makes salient the fact that tourists in Ladakh have not had the same cultural experiences as Ladakhis. Few tourists have belonged to a “developing” community and been gazed upon and photographed by wealthy people who say they want to see and admire the local "culture.” Cohen et al. (1992:215) suggest that there is always a degree of ambiguity in the photographerphotographee interaction about how each views the other, and that this ambiguity increases if the photographer and photographee are not familiar with each other. In the case of Ladakh, tourists and locals are certainly not familiar with each other: they are separated by divergent economic interests, a linguistic barrier and by the fact that they are embedded in distinct cultural streams. Given this lack of shared cultural experience between tourists and Ladakhis it should not be surprising that that tourists are ill-equipped to take the perspective Ladakhis have with respect to tourist photography. The question to ask is not whether tourists are taking the perspective of Ladakhis, but instead, what experiences are tourists generalizing and attributing to Ladakhis? 
I want to argue that tourists are not reflecting upon themselves from the actual perspective of Ladakhis, but instead are reacting to themselves in the same way that they (the tourists) react toward other tourists. That is to say, the tourists generalize their own reaction toward tourist photographers and attribute this same reaction to Ladakhis. In order to illustrate this argument, the analysis needs to turn away from Ladakhis, and turn back to the perspective of tourists. How do tourists represent other tourists in general and tourist photographers in particular? And, is there a similarity between this representation and tourists’ conceptions of the Ladakhi reverse gaze?

\section{TOURISTS, TRAVELERS AND POST-TOURISTS}

Generally speaking, tourists are quite self-reflective about tourism (MacCannell 2001; Prebensen et al. 2003). In Ladakh they are especially concerned about the way in which tourists interact with locals. Many tourists that I spoke to referred to the history of colonialism and were strenuous in their efforts to compliment Ladakh and Ladakhis. However, when talking about other tourists, there do not seem to be any norms of political correctness that curtail scorn and denigration. Indeed, it is difficult to understate the extent to which tourists, in Ladakh, are critical of other tourists, especially tourist photographers. The following excerpt, from a discussion I had with two backpackers, illustrates the general way in which tourist photographers are portrayed.

Travis: One of the worst and most degrading things that I saw, the other day, was an old guy, and some tourists said “can you pose for a photo for us?” and he was like “yeah, I’m having a break why not” and so the girl like went up and said “can 
you hold your prayer wheel like this, and hold your mala [prayer beads] up," she basically made him pose, and he sort of put a fake smile on, and she took the photo, and then he relaxed again

Tony: That is so pointless

Travis: I just felt bad for him

Travis narrates the tourist photographer as getting an elderly Ladakhi man to "pose" so that she could take a photograph. The photographer is portrayed as taking something, a picture, and giving only inconvenience and disrespect in return. However, there is a degree of justice in the narrative, for the tourist photographer does not get a genuine photograph, she only gets a "fake smile.” The inauthenticity of tourist experiences is a recurring theme (see Taylor 2001), especially the inauthenticity experienced by Other tourists. In the extract one can clearly see Tony and Travis scorning both the intrusiveness of the tourist photographer and the inauthentic outcome.

The stereotypical representation of the ignorant, foolish, consumerist and duped tourist, one who methodically "does" the sights, enclosed in an insular bubble, has been an object of ridicule since at least the mid 19th century (Löfgren 1999:38). Today a similar image is propagated through the mass media. From Tintin to the National Lampoon's European Vacation, tourists are a source of humor. It is easy for Westerners to participate in, and cultivate, such a view of tourists while securely situated in one's home country as a local. But a problem arises when these Westerners go on holiday: then Self becomes a tourist and the tables turn. The pejorative representation of Other threatens to return and be applied to Self. Accordingly, tourists are left with the difficult task of maintaining a 
positive sense of Self, while simultaneously engaging in the usual critique of tourists. The following excerpt illustrates how a Dutch man negotiates this task.

AG: What pictures have you taken?

Marten: Mostly of landscapes! (laugh) and gonpa! [Buddhist monastery] And a few times of people [...] also of people, em, really sneaky, but em, but em, I’m sure they don't know, but it’s different from shoving such a lens [gesturing with hands] in someone’s face from a meter distance

AG: If you were going to photograph people, who would you choose to photograph?

Karen: The old women, of course, and old men

AG: Why?

Karen: Because they look nice

Marten: Their characteristics, (pause) but when you want to take a picture of an old woman, try to have a little relation with them, not like run through the country and take some pictures, like Japanese! (pause) I am afraid to take photos, I can imagine how offensive it would be

Marten's initial response and laugh to my question reveals the anxiety that probing tourists’ photographic practices can evoke. Many tourists seemed to be ashamed of the fact that they had taken photographs of Ladakhis. Like Marten, tourists were more comfortable talking about landscape photographs or the ignorance of other tourists than about their own efforts to photograph Ladakhi people. My asking Marten about his own photographing practices threatens to position him as one of the multitude of scorned 
tourist photographers. Rather than defend the practices of tourist photographers, Marten tries to differentiate his own practices from those of Other tourist photographers. First, he admits to having taken some "sneaky" photographs of local people, and immediately he asserts that this is quite different from the practices of other tourists. Other tourists "shove” long lenses in the face of locals "from a meter distance.” It is implied that such intrusive photography is undesirable, and Marten avoids being intrusive by taking "sneaky" photographs. Second, Marten criticises tourists who "run through the country and take some pictures.” The problem with such tourist behaviour is that it fails to establish "a little relation” with the locals. It is implied that Marten moves at a slower pace and invests the time to form constructive relations with locals, and thus that he should not be positioned along with the majority of ignorant tourist photographers.

There are several discursive positions that tourists try to claim when differentiating themselves from Other tourist photographers. Some tourists make a distinction between travelers and tourists. Travelers claim to stay for longer, take up a Ladakhi lifestyle, respect the local culture and establish personal relationships with Ladakhis. In the later part of Marten's excerpt, one can see Marten trying to claim this traveler identity position. Another identity position that tourists try to claim is that of the post-tourist (Feifer 1985). Post-tourists tour the tourists or embrace the usual tourist practices in self-mockery. For example, when I asked one English tourist why he took a photograph of a gonpa, he told me, "because that's what you are supposed to do!" Each of these favored positions is constructed in opposition to an image of the "typical tourist." As with ethnographies, one can read the ideal to which Self strives through Self's representation of Other (Vidich and Lyman 1994). Thus, for example, the tourist who has contempt for tourist photographers 
who do not engage with the local culture or people is implicitly claiming a traveler identity. Equally, the tourist who mocks the naivety of other tourists who see authenticity where there is, they claim, only inauthenticity, is implicitly claiming a post-tourist identity.

The evidence from Ladakh supports Crick’s (1989:307) general observation, that "many tourists claim that they are not tourists themselves and that they dislike and avoid other tourists.” Tourists criticize and scorn other tourists, especially tourist photographers (see also Prebensen et al. 2003). This is a peculiar form of Othering (Rabinowitz 2002) because Self is technically a tourist, and usually a tourist with a camera, and thus Self is vulnerable to positioning in the same way as the Other. Tourists who stigmatize other tourists must position themselves carefully to avoid falling into the stigma of their own making.

Having outlined the ways in which tourists talk about other tourists, I now want to return to the argument by illustrating that the reverse gaze is in fact best understood as tourists' own representation of tourist photographers turned upon Self. Consider, first, the characteristics of the reverse gaze as perceived by tourists. When the reverse gaze catches the tourist photographer, the tourist feels uncomfortable, shamed, and embarrassed. Tourists perceive that Ladakhis find being photographed by tourists "horrible" as it makes them “feel freakish.” I have argued that tourists perceive tourist photography to be more undesirable for Ladakhis than it actually is. Next, consider the way in which tourists represent Other tourist photographers. There is widespread scorn and derision of tourist photographers because taking photographs is perceived to be intrusive, degrading and 
inauthentic. Notice the similarity between the reverse gaze and tourists' own perception of tourist photographers. Tourists' own perception of tourist photographers contains enough scorn and derision to be able to account for the discomforting effects of the reverse gaze upon tourists. This discomfort is arguably compounded by the fact that it simultaneously reveals a contradiction between tourists' idealized self-position (traveler or post-tourist) and their actual behavior (just another tourist with a camera). The reverse gaze by making salient the tourists' object state as a tourist photographer invites the tourist to position themselves as a typical tourist, and thus challenges any claim to be a traveler or posttourist.

That the reverse gaze is in fact a part of the tourists' own gaze turned upon itself can be illustrated by reconsidering the comments of Travis and Marten. Both Travis and Marten make assumptions about the attitude that Ladakhis have toward being photographed. Travis says, "I just felt bad for him," indicating that the elderly Ladakhi man felt degraded by the photograph. Equally, Marten says “I can imagine how offensive it would be.” But who is it who feels that blatant photography of Ladakhis is either "degrading" or "offensive"? The answer, I am suggesting, is not primarily the Ladakhis being photographed, but rather Travis and Marten. That is to say, in order to make some sense of what Ladakhis may feel about tourist photographers, both Travis and Marten are generalizing, or attributing, their own opinion of tourist photographers to Ladakhis. 


\section{THEORIZING THE REVERSE GAZE}

The present interpretation of the reverse gaze - that it is in fact comprised of tourists' own perception of other tourists turned toward Self - sheds new light on the question with which this article began: why does the reverse gaze cause such discomfort for tourist photographers?

When the tourist photographer is caught by the reverse gaze, either by a glance or by the local person pointing a camera back at the tourist, the tourist acquires a spoilt self because the tourist assumes that the reverse gaze reveals a disapproving attitude. The reverse gaze constitutes the emerging tourist self because that self image is, at least partly, dependent upon how Self perceives Other to perceive Self (Cooley 1902; Mead 1913). Given that tourists cannot take the actual perspective of Ladakhis, they generalize their own attitude toward tourist photographers to the Ladakhis. Tourists' scorn for other tourists is the basis for their own discomfort and embarrassment. The reverse gaze, then, conspires to encourage tourists to scorn themselves. The scorn initially directed at Other tourists returns, and becomes directed at Self. It follows that if tourists widely believed that tourist photography was a gesture of recognition toward Ladakhis, and tourists attributed this understanding to Ladakhis, that the reverse gaze would create a very different set of feelings for tourists.

It is possible to speculate that the discomfort produced by the reverse gaze is compounded by a second factor. Tourists’ attempts to positively differentiate themselves from other tourists are liable to lead to contradictions. It is easy enough to claim, at a discursive level, 
the identity position of a "traveler," or "post-tourist," but it is more difficult to maintain this positioning in practice. There is often a contradiction between the identity positions which tourists claim and the practices they enact. Examples of such contradictions are numerous: the female tourist who lent her camera to the Ladakhi woman at the Women's Alliance festival had previously been using her own camera to take photographs of Ladakhis. Travis criticizes another tourist for photographing an old man, but his collection of holiday photographs includes pictures of elderly Ladakhis posing for him. Marten, who also criticizes other tourists, begins by saying that he takes "sneaky" photographs and then fails to see the contradiction when he later argues that tourists should have "a little relation” with the Ladakhis - it is difficult to have such a relation if one is taking only "sneaky” photographs. The prevalence of these latent contradictions may help to explain the discomfort of the reverse gaze for tourists. The reverse gaze may make the tourist photographer aware of his or her own contradictions. The reverse gaze catches tourists in one of the most typical tourist practices: taking a photograph of a local. Thus the reverse gaze, by making salient this practice, is also likely to challenge tourists' attempts to positively differentiate themselves from Other tourists.

Another dynamic that could underlie the discomforting power of the reverse gaze is the contradiction between tourists' often explicit romanticism of Ladakhi culture and either a latent superiority or a fear of feeling superior. Why are tourists interested in photographing Ladakhis, especially the more traditional Ladakhis, anyway? Admiring "traditional” cultures is filled with ambiguity. Romanticism, voyeurism and superiority are delicately balanced (Parameswaran 2002). I am not suggesting that tourists are "secretly" racist, but simply that tourists' imagination of Ladakh is embedded in a complex stream of 
newer romantic representations (Bishop 1989) and older more Orientalist representations (Said 1978; Bray 1997). With such a multiplicity of co-existing representations tourists may be uncertain about whether or not they have lingering and latent Orientalist attitudes. As Bem (1972) has argued, we do not know our attitudes by simple introspection: often our attitudes are ambiguous and vague, and in such cases we rely upon our own observations of how we act to infer our own attitudes. It is possible then, that the reverse gaze, by raising the salience of the act of photography for tourists, encourages tourists to question their own interest in, and motivation to photograph, "traditional" people. Here again, however, the key dynamic is not tourists taking the actual perspective of Ladakhis, but rather, tourists turning their own gaze upon themselves.

\section{CONCLUSION}

Modernity is based on a hegemony of vision (Levin 1993). Tourism is one crystallization of this hegemony (Crawshaw and Urry 1997). Before modern times, the Grand Tour was based on learning languages, speaking to locals, and gathering facts (Chaney 1998). But during the 18th century, the emphasis of tourism shifted from the ear to the eye (Adler, 1989). The ascendancy of vision within tourism, as with other realms of modernity (e.g., Foucault 1977), has been associated with power relations. Urry's (1990) concept of the tourist gaze, for example, directs our attention toward the domination of tourists and locals alike (MacCannell 2001). Moreover, much of the literature is framed in terms of the effects or impacts of tourists on locals, or, the impact of travel on tourists and pilgrims (Kray 2002). However, Foucault wrote that power is everywhere and that even the most apparently powerless person is a node in the system of power. Accordingly, I have tried to 
articulate the power of the reverse gaze of locals as a necessary counter-balance to the gaze of the tourist photographer. The reverse gaze plays a constitutive part in the dynamic emergence of the situated tourist self. The reverse gaze has the power to turn a buoyant traveler into a discomforted tourist. It can create shame and embarrassment.

However, while the reverse gaze does clearly disrupt tourist photographers, this is not a power that the Ladakhis have seized upon, indeed, to some extent Ladakhis are only a vehicle for this power. The reason for this is that the social psychological mechanism underlying the reverse gaze relies not on the actual representations of Ladakhis, but rather on tourists' own representations of tourist photography which they in turn attribute to Ladakhis. Accordingly, we must augment the earlier definition of the reverse gaze: the reverse gaze refers to the gaze of the photographee on the tourist photographer as perceived by the tourist photographer. One could imagine alternative interactions where the reverse gaze would produce quite different social emotions. For example, the reverse gaze of a Taiwanese woman being photographed by her suitor may create feelings of romance and desire (Adrian 2004). However, in the case of tourists in Ladakh, that is, tourists who are touring a "traditional" community, the reverse gaze is most likely to produce discomfort. Whether this discomfort is transient embarrassment, guilt, or shame depends upon the context and on the tourist. The tourist, I suggest is especially important because it is their own positioning of Other tourist photographers that will, through the reverse gaze, return to constitute the discomfort.

The present analysis contributes to the debate concerning subjectivity and agency within Urry's concept of the tourist gaze. MacCannell (2001:30) has argued that the concept of 
the tourist gaze denies tourist agency and subjectivity, because the gaze is seen to determine tourist perception and thought. Thus, MacCannell has argued for the existence of a "second gaze" within tourist subjectivity. The second gaze is a part of tourists' subjectivity that has as its object the tourist gaze. It questions the tourist gaze, and asks how tourist experiences have been constructed. The second gaze questions the main touristic attraction and asks what has been left out. There are several empirical examples of this second gaze (e.g., Kirschenblatt-Gimblett 1998) or “questioning gaze” (Bruner 2005:95). Incorporating the second gaze into the concept of the tourist gaze reconstructs the tourist as a dialogical and questioning subject. The contribution of the present article to this discussion lies in a specification of how the dialogical second gaze may arise within a given setting. While the tourist gaze is directed outward, toward the people and places toured, the second gaze is directed inward, toward the experiencing tourist. The reverse gaze can facilitate the second gaze by redirecting the gaze of the tourist away from the toured and back to the tourist, making contradictions salient and questioning motivations.

The interesting thing about the reverse gaze, from the point of view of psychological anthropology, is that it triggers a moment of re-positioning. It is a dynamic social interaction that turns self-claimed travelers and post-tourists into "typical tourists.” While recent research has considered how people claim social positions while being positioned by Other (Holland et al., 1998), how new positions consolidate, or “thicken,” over the course of months into new identities (Wortham 2004), and how positions are artificially created (Adrian 2004), the present analysis attempts to articulate some of the micro social psychological dynamics that instigate re-positioning. The above analysis suggests that in the moment of the reverse gaze, there is a whole change in the tourists' orientation and 
meaning structure. Before the gaze the situation is framed by the discourse of "culture" and "tradition." The tourists' attention is fully absorbed in the visual consumption of the other and the technicalities of photography. The reverse gaze seems to make salient a completely different semiotic frame, which foregrounds the activity of photography as a questionable tourist activity.

Research on positioning usually focuses upon the negotiation between Self claiming a position and Self being positioned by Other (Holland and Leander 2004). The present analysis has added a degree of complexity to the latter concept of "being positioned." In what sense can we say that tourist photographers in Ladakh are being positioned by Ladakhis as disrespectful tourists? The answer to the question depends upon one's perspective: tourists often feel positioned as disrespectful tourists by the reverse gaze of Ladakhis, but Ladakhis are rarely actually positioning tourists in this way. Thus instead of dealing, minimally, with two perspectives, we must minimally consider three perspectives: Self's perspective on Self, Other's perspective on Self, and Self's perspective on Other's perspective on Self. Although the divergence between Ladakhis' perspective on tourists and tourists' understanding of the Ladakhis perspective is particularly evident, probably due to the language barrier, it is likely that a similar divergence may be relevant to understanding other contexts.

Finally, the present analysis is not only about the contradictory positionings that arise within the social field, between different social actors, it is also about multiple positionings within a single actor. We know, from dialogical research that has developed the work of Bakhtin, that collective discourses and even individual utterances can be 
multivoiced. The present analysis concerns a peculiar form of multivoicedness. Tourists usually claim, at a discursive level, a position that is superior to that of the "average tourist” or "typical tourist." However, their actions are likely to run counter to these claims - the majority of tourists cannot act in non-average or non-typical ways. Moreover, there is a contradiction in how tourists position themselves compared to other tourists: Many tourists criticize the behavior of other tourists despite behaving in this same way themselves. In contemporary society, genuine dialogicality is perceived to be a threat to the unity and integrity of the self, and thus there is a premium on being consistent and monological (Holquist 1990). While most of the time these contradictory tendencies coexist within tourists quite peacefully, there are times when the contradiction becomes salient. Part of the peculiar discomfort of the reverse gaze for tourists in Ladakh, I have suggested, is the potential of the reverse gaze to make salient - if briefly - this contradiction. 


\section{ENDNOTES}

${ }^{1}$ The fieldwork, conducted between 1997 and 2005 (more than 12 months in total), included ethnographic observation, group discussions with twenty-five diverse tourist groups and thirty-nine diverse Ladakhi groups, and numerous interviews. All of the group discussions and most of the interviews were recorded on audiocassette and transcribed. The group discussions with tourists were conducted in naturalistic settings - restaurants, bars and guesthouses. The group discussions with Ladakhis were moderated by Ladakhi colleagues. The discussions and interviews centred upon how both tourists and Ladakhis represent themselves, each other, and the other's representations of them. All the discussions were informal with the aim of creating as much intragroup dialogue (i.e., not researcher led dialogue) as possible so as to generate data approximating naturalistic conversation. The purpose of the research was to study the emergence of novel tourist and Ladakhi identities through tourist-Ladakhi interaction.

${ }^{2}$ Writing about "tourists" is problematic for two reasons. Firstly, the category does not refer to a stable group - most people are tourists at some point in time, and nobody is a tourist all of the time. Secondly, because so many people become tourists at some point in time, the category itself includes a great diversity of people. That is to say, there are many types of tourist (Cohen 1974). Whenever one makes a claim about "tourists" there is always an exception. In my use of the term, I knowingly sacrifice subtlety in order to outline general, but not universal, characteristics of the reverse gaze. 


\section{ACKNOWLEDGEMENTS}

I would like to acknowledge the financial support of the Economic and Social Research Council and Peterhouse, Cambridge, and I would especially like to acknowledge the intellectual support of Tara Sinclair, Flora Cornish, Gerard Duveen, João Salgado, Edward Bruner, the editor, Janet Dixon Keller, and a particularly thorough anonymous reviewer. Finally, I would like to thank all the tourists and Ladakhis who were involved in this research, especially Chakdor Spon and Manish Enn. 


\section{REFERENCES}

Adler, Judith

1989 Travel as Performed Art. American Journal of Sociology 94:1366-1391.

Adrian, Bonnie

2004 The Camera’s Positioning: Brides, Grooms, and their Photographers in

Taipei’s Bridal Industry. Ethos 32(2): 140-163.

Barth, Fredrik

1969 Introduction. In Ethnic Groups and Boundaries: The Social Organization of Cultural Difference. F. Barth, ed. Pp. 9-38. London: George Allen \& Unwin.

Bem, Daryl J.

1972 Self-Perception Theory. In Advances in Experimental Social Psychology Vol. 6. L. Berkowitz, ed., Pp. 1-62. New York: Academic Press.

Bishop, Peter

1989 The Myth of Shangri-La: Tibet, Travel Writing, and the Western Creation of a Sacred Landscape. Berkeley: University of California Press.

Blumer, Herbert

1969 Symbolic interactionism. Berkeley: University of California Press.

Bray, John

1997 The Roman Catholic Mission in Ladakh, 1888-1898. In Recent Research on Ladakh 6. H. A. Osmaston and N. Tsering, eds. Pp. 29-43. Delhi: Motilal Banarsidass Publishers.

Bruner, Edward M. 
2005 Culture on Tour. Chicago: The University of Chicago Press.

Charon, Joel M.

1979 Symbolic Interactionism. London: Prentice-Hall.

Chaney, Edward

1998 The Evolution of the Grand Tour. London: Frank Cass.

Cohen, Erik

1974 Who is a Tourist? A Conceptual Clarification. The SociologicalReview, 22:527-555.

Cohen, Erik, Yeshayahu Nir and Uri Almagor

1992 Stranger-Local Interaction in Photography. Annals of Tourism Research, 19:213233.

Cooley, Charles H.

1902 Human Nature and the Social Order. New York: Charles Scribner's Sons.

Crawshaw, Carol and John Urry

1997 Tourism and the Photographic eye. In Touring Cultures: Transformations in Travel and Theory. C. Rojek and J. Urry, eds. Pp. 176-195. London: Routledge.

Crick, Malcolm

1989 Representations of International Tourism in the Social Sciences: Sun, Sex, Sights, Savings and Servility. Annual Review of Anthropology 18:307-344.

Dodin, Thierry and Heinz Räther

2001 Imagining Tibet: Perceptions, Projections, and Fantasies. Boston: Wisdom Publications.

Edelmann, Robert. J.

1987 The Psychology of Embarrassment. New York: Wiley. 
Feifer, Maxine

1985 Going Places: The Ways of the Tourist from Imperial Rome to the Present Day. London: Macmillan.

Foucault, Michel

1977 Discipline \& Punish: The Birth of the Prison. New York: Vintage Books.

Galwan, Rassul

1923 Servant of Sahibs: A Book to be Read Aloud. Cambridge: W. Heffer \& Sons Ltd.

Gillespie, Alex

2005 G.H. Mead: Theorist of the social act. Journal for the Theory of Social Behaviour 35(1):19-39.

Goffman, Erving

1959 The Presentation of Self in Everyday Life. London: Penguin.

Government of Jammu and Kashmir

1998 Ladakh Region Statistics. Unpublished manuscript.

Hobsbawm, Eric, and Terence Ranger

1983 The Invention of Tradition. Cambridge: Cambridge University Press.

Holland, Dorothy, Debra Skinner, William Lachicotte Jr. and Carole Cain

1998 Identity and Agency in Cultural Worlds. Cambridge, MA: Harvard University Press.

Holland, Dorothy and Kevin Leander

2004 Ethnographic Studies of Positioning and Subjectivity: An Introduction. Ethos 32(2):127-139.

Holquist, Michael

1990 Dialogism: Bakhtin and his world. London: Routledge. 
Jina, Prem S.

1994 Tourism in Ladakh Himalaya. New Delhi: Indus Publishing Company.

Kirschenblatt-Gimblett, Barbara

1998 Destination Culture: Tourism, Museums, and Heritage. Berkeley: University of California Press.

Kray, Christine A.

2002 The Pentecostal Re-Formation of Self: Opting for Orthodoxy in Yucatán. Ethos 29:395-429.

Levin, David M.

1993 Modernity and the Hegemony of Vision. Berkeley: University of California Press.

Lopez, Donald S.

1998 Prisoners of Shangri-La: Tibetan Buddhism and the West. Chicago: University of Chicago Press.

Löfgren, Orvar

1999 On holiday: A History of Vacationing. Berkeley: University of California Press.

Lundgren, David C.

2004 Social Feedback and Self-Appraisals: Current Status of the Mead-Cooley Hypothesis. Symbolic Interaction 27(2):267-286.

MacCannell, Dean

2001 Tourist Agency. Tourist Studies 1(1):23-38.

Mead, George H.

1913 The Social Self. Journal of Philosophy, Psychology and Scientific Methods 10(14):374-380.

1925 The Genesis of Self and Social Control. International Journal of Ethics 35:251- 
277.

Parameswaran, Radhika

2002 Local Culture in Global Media: Excavating Colonial and Material Discourses in National Geographic. Communication Theory 12:287-315.

Philp, Janette and David Mercer

1999 Commodification of Buddhism in Contemporary Burma. Annals of Tourism Research, 26(1):21-54.

Prebensen, Nina K., Svein Larsen and Birgit Abelsen

2003 I'm Not a Typical Tourist: German Tourists' Self-Perception, Activities and Motivations. Journal of Travel Research, 41:416-420.

Rabinowitz, Dan

2002 Natives with Jackets and Degrees. Othering, Objectification and the Role of Palestinians in the Co-Existence Field in Israel. Social Anthropology 9:65-80. Said, Edward W.

1978 Orientalism: Western Conceptions of the Orient. London: Penguin.

Shrauger, Sidney J. and Thomas J. Schoeneman

1979 Symbolic Interactionist view of Self-Concept: Through the Glass Darkly. Psychological Bulletin 86:549-573.

Singh, Harjit

1997 Ecology and Development in High Altitude Ladakh: A Conflicting Paradigm. In Recent Research on Ladakh 6. H. A. Osmaston and N. Tsering, eds. Pp. 239-250. Delhi: Motilal Banarsidass Publishers.

Taylor, John P.

2001 Authenticity and Sincerity in Tourism. Annals of Tourism Research, 28:7-26. 
Tilley, Christopher

1999 Metaphor and Material Culture. Oxford: Blackwell Publishers.

Urry, John

1990 The Tourist Gaze: Leisure and Travel in Contemporary Societies. London: Sage Publications.

van Beek, Martijn, and Kristoffer B. Bertelsen

1997 No present without past. In Recent Research on Ladakh 7. T. Dodin and H. Räther, eds. Pp. 43-66. Bonn: Ulmer Kulturanthropologische Schriften.

Vidich, Arthur J., and Stanford M. Lyman

1994 Qualitative Methods: Their History in Sociology and Anthropology. In Handbook of Qualitative Research. N. K. Denzin and Y. S. Lincoln, eds. Pp. 23-59. London: Sage Publications Ltd.

Wangyal, Sonam

1997 Political evolution in post independence Ladakh. In Recent Research on Ladakh 7.

T. Dodin and H. Rather, eds. Pp. 485-492. Bonn: Ulmer Kulturanthropologische Schriften.

Wortham, Stanton

2004 From Good Student to Outcast: The Emergence of a Classroom Identity. Ethos 32(2):164-187. 